\title{
Brain-Stimulation Reward Thresholds Raised by an Antisense Oligonucleotide for the M5 Muscarinic Receptor Infused near Dopamine Cells
}

\author{
John S. Yeomans, ${ }^{1}$ Junichi Takeuchi, ${ }^{1}$ Marco Baptista, ${ }^{1}$ Donna D. Flynn, ${ }^{2}$ Karen Lepik, ${ }^{1}$ Jose Nobrega, ${ }^{1}$ \\ James Fulton, ${ }^{1}$ and Martin R. Ralph ${ }^{1}$ \\ ${ }^{1}$ Department of Psychology, University of Toronto, Toronto, Ontario, Canada M5S 3G3, and 2Department of Molecular and \\ Cellular Pharmacology, University of Miami School of Medicine, Miami, Florida 33101
}

\begin{abstract}
Oligonucleotides targeting M5 muscarinic receptor mRNA were infused for $6 \mathrm{~d}$ into the ventral tegmental area of freely behaving rats trained to bar-press for lateral hypothalamic stimulation. The bar-pressing rate was determined at a range of frequencies each day to evaluate the effects of infusions on reward. M5 antisense oligonucleotide (oligo) infusions increased the frequency required for bar pressing by $48 \%$ over baseline levels, with the largest increases occurring after 4-6 d of infusion. Two control oligos had only slight effects (means of 5 and $11 \%$ for missense and
\end{abstract}

sense oligos, respectively). After the infusion, the required frequency shifted back to baseline levels gradually over 1-5 d. Antisense oligo infusions decreased M5 receptors on the ipsilateral, but not the contralateral, side of the ventral tegmentum, as compared with a missense oligo. Therefore, M5 muscarinic receptors associated with mesolimbic dopamine neurons seem to be important in brain-stimulation reward.

Key words: M5; muscarinic; cholinergic; dopamine; self-stimulation; reward; oligodeoxynucleotide
Dopamine-containing neurons of the ventral tegmental area (VTA) and substantia nigra (SN) are important for brain-stimulation and drug rewards (Phillips and Fibiger, 1978; Gallistel and Karras, 1984; Wise, 1978; Stellar and Corbett, 1989). Because rewarding stimulation of the medial forebrain bundle directly activates mainly nondopaminergic myelinated axons, dopamine neurons are believed to be indirectly activated in brain-stimulation reward (Yeomans et al., 1985b; Bielajew and Shizgal, 1986).

One important input to dopamine neurons is from cholinergic neurons of the pedunculopontine and laterodorsal tegmental nuclei, which monosynaptically activate dopamine neurons via nicotinic and muscarinic receptors (Clarke and Pert, 1985; Fujimoto et al., 1990; Bolam et al., 1991; Lacey et al., 1990; Futami et al., 1995). Cholinergic agonists nicotine and carbachol injected near dopamine cells increase dopamine release in the dorsal striatum or nucleus accumbens (Imperato et al., 1986; Blaha and Winn, 1993; Blaha et al., 1996).

Cholinergic receptors in the VTA are important for brainstimulation reward. Hypothalamic brain-stimulation reward induces acetylcholine release in the VTA (Rada et al., 2000). Acetylcholine in the VTA increases bar-pressing rates for brainstimulation reward (Redgrave and Horrell, 1976). Muscarinic blockers in the VTA approximately double thresholds for brainstimulation reward, whereas nicotinic blockers increase thresholds by $\sim 20 \%$ (Yeomans et al., 1985a; Kofman et al., 1990; Yeomans and Baptista, 1997). Nicotinic receptors in the VTA are believed important for the mediation of nicotine self-administration (Corrigall and Coen, 1989; Corrigall et al., 1992, 1994), nicotineinduced locomotion (Museo and Wise, 1990; Reavill and Stolerman, 1990), and nicotine-induced dopamine release in rats (Nissell et al., 1994).

\footnotetext{
Received May 2, 2000; revised Aug. 7, 2000; accepted Sept. 6, 2000.

This work was supported by grants from the National Science and Engineering Research Council of Canada and Ontario Schizophrenia Foundation to J.S.Y., the Ontario Mental Health Foundation to J.S.Y and to J.N., by United States Air Force Office of Scientific Research Grant F490-92-J-0517 to M.R.R, and by Grants AG12738 and NS19065 to D.D.F. We thank E. Spironello, M. Fara-on, M. Priebe, S. Steidl, and R. Raymond for technical assistance.

Correspondence should be addressed to Dr. John Yeomans, Department of Psychology, University of Toronto, Toronto, Ontario Canada M5S 3G3. E-mail: yeomans@psych.utoronto.ca.

Copyright (C) 2000 Society for Neuroscience $0270-6474 / 00 / 208861-07 \$ 15.00 / 0$
}

Five muscarinic receptor genes have been cloned (Kubo et al., 1986; Bonner et al., 1987, 1988; Peralta et al., 1987), and their receptors have been localized in the rat brain (Levey et al., 1991). In the VTA and SN, the only mRNA found for these muscarinic receptors is for the rare M5 subtype (Vilaro et al., 1990; Weiner et al., 1990; Yasuda et al., 1993). M5 receptors and mRNA are associated with dopamine cells and D2 receptors (Weiner et al., 1990; Flynn et al., 1997) and are lost when dopamine cells are killed with 6-hydroxydopamine (Vilaro et al., 1990; Flynn et al., 1997).

To test whether M5 receptors are crucial for brain-stimulation reward, in this study an M5 antisense oligonucleotide was infused into the VTA to inhibit production of the M5 receptor. (No selective agonist or antagonist at the M5 receptor is available.) Oligonucleotides (oligos) are short DNA molecules that can be transported into neurons and arrest the translation of new protein by hybridizing with the complementary mRNA (Crooke, 1992; Wagner, 1994; Wahlestedt, 1994). Oligos injected into the brain can alter the production of selected proteins (McCarthy et al., 1993; Wahlestedt et al., 1993; Zang et al., 1994; Neckers et al., 1995) and alter behaviors consistent with the functions of those proteins (Wahlestedt et al., 1993; Zhang and Creese, 1993; Adams et al., 1994; Akabayashi et al., 1994; Ogawa et al., 1994; Tischmeyer et al., 1994; Neckers et al., 1995; Phillips and Gyurko, 1995).

Parts of this paper have been published previously (Yeomans et al., 1995).

\section{MATERIALS AND METHODS}

Oligonucleotides. Oligos were synthesized on an Applied Biosystems (Foster City, CA) DNA Synthesizer 394 and column purified. Concentrations were determined by optical absorbance and further verified by ethidium bromide staining on agarose gel.

The oligo sequences were based on a rat M5 receptor cDNA sequence (Bonner et al., 1988). The M5 sense oligo chosen was a copy of a 21-base sequence of the rat M5 receptor gene, near the 5' end of the cDNA sequence, including the last 6 bases before the start codon and the next 15 bases in the coding region of the gene. The M5 antisense oligo was the complement to the M5 sense, designed to prevent translation of the M5 receptor protein by hybridizing with the initiation region of the mRNA transcribed from the M5 receptor gene. The M5 mismatched antisense ("missense") oligo included the same bases as the M5 antisense oligo, but four bases were changed in position. This was accomplished by exchanging two bases with two other bases (the first pair moved by one base position and the second pair moved by two base positions). All oligos had unmodified (i.e., phosphodiester) backbones, which are believed to be less toxic 

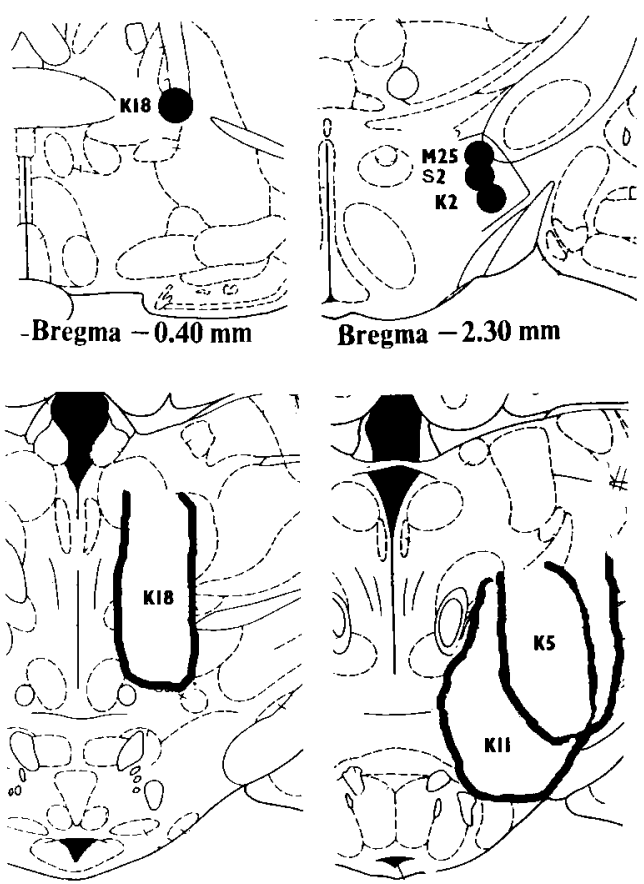

Bregma $-4.30 \mathrm{~mm}$

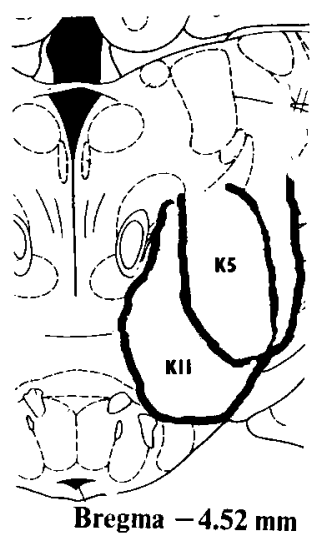

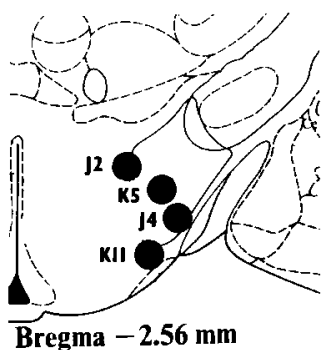

Bregma $-2.56 \mathrm{~mm}$

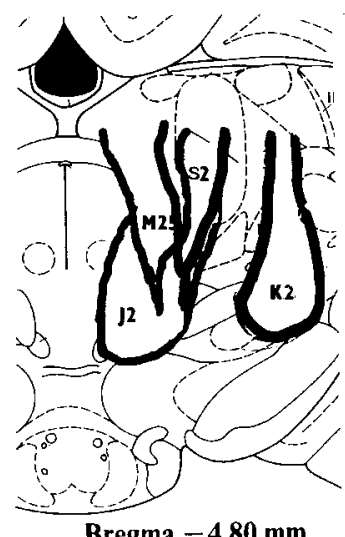

Bregma $-4.80 \mathrm{~mm}$
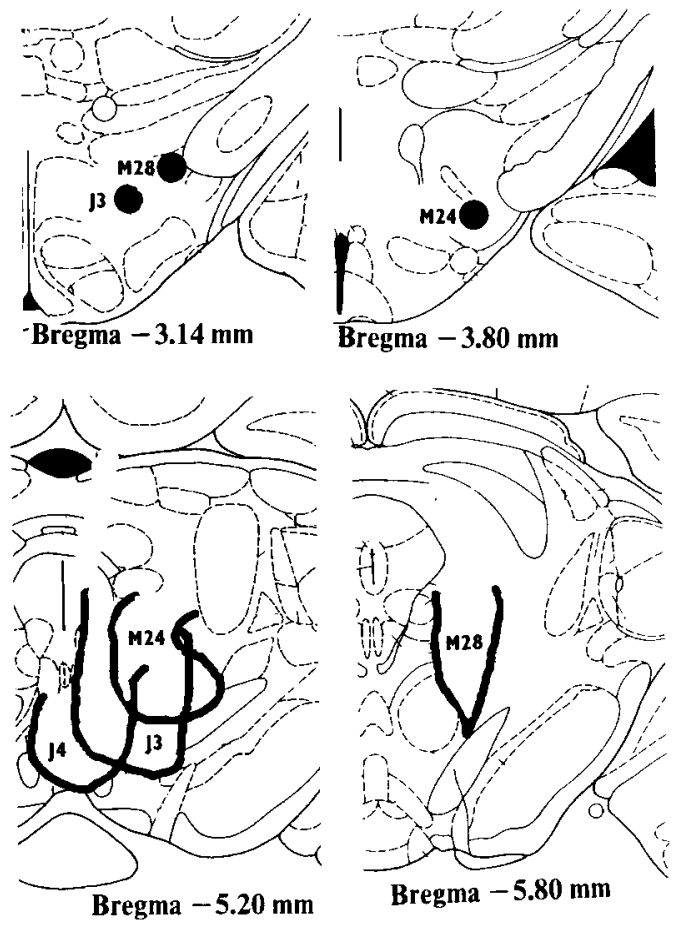

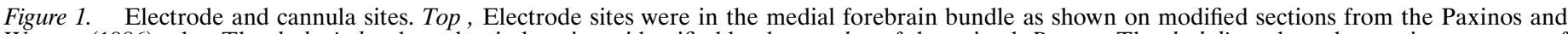

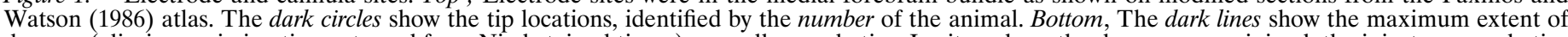

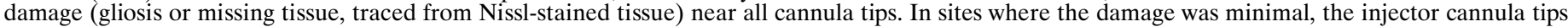
were observed as a pointed region.

than thionated backbones (Wahlestedt, 1994). The M5 sense control assesses whether direct inhibition of the gene occurs; the M5 missense control assesses whether the inhibition is sequence-specific for the M5 mRNA. The sequences were as follows: M5 sense, 5'-GCC AGG ATG GAA GGG GAG TCT-3'; M5 antisense, 5'-AGA CTC CCC TTC CAT CCT GGC-3'; and M5 missense, 5'-AGA CTC CCC TTC CAC TCG GTC-3'

The GenBank program, version 87 , was surveyed to compare sequences of 24,095 genes presently sequenced in rodents with the 3 sequences used here. None showed more identity with the M5 antisense oligo than did the control missense oligo (14 continuous bases identical and 17 of 21 total bases identical), although several showed similar levels of identity. For example, the "mouse insulin-like growth factor II" had 14 continuous bases that matched. The most interesting, the "rat G-protein-coupled muscarinic potassium channel" also had 14 continuous bases that matched. The probability that any known or unknown rat gene can be identical with any 21 -base sequence is $\sim 3$ billion divided by 4 to the 21 st power, which is $<1$ in 1000 .

Alzet osmotic minipumps (model 2002; Alza, Palo Alto, CA) were filled with $200 \mu \mathrm{l}$ of an oligo solution diluted in artificial CSF to a final concentration of $10 \mu \mathrm{M}$ oligo and then primed (preincubated) at $37^{\circ} \mathrm{C}$ in saline for at least $15 \mathrm{hr}$ before implantation under ketamine and xylazine anesthesia. Each pump released this solution at a steady rate of $0.5 \mu \mathrm{l} / \mathrm{hr}$ or $30 \mathrm{ng}$ of oligo/hr. These continuous infusions are more efficient than are repeated invasive injections and can maintain a more stable concentration of oligo.

Procedure. The rats tested in this experiment had electrodes placed in the lateral hypothalamus and cannulae placed in the VTA, aimed for sites where injections of antimuscarinic agents inhibit brain-stimulation reward (Yeomans et al., 1985a; Kofman and Yeomans, 1989; Kofman et al., 1990). Surgery was performed under pentobarbital anesthesia $(60 \mathrm{mg} / \mathrm{kg})$. The 250- $\mu \mathrm{m}$-diameter stainless-steel electrodes were insulated with Epoxylite except for a hemispherical exposed tip. The electrodes were aimed for the medial forebrain bundle at the level of the lateral hypothalamus $(2.6 \mathrm{~mm}$ posterior to bregma, $1.8 \mathrm{~mm}$ lateral to the midline, and $9.2 \mathrm{~mm}$ below dura, with the lambda-bregma line placed horizontally). A guide cannula (Plastics Products, Roanoke, VA) $0.7 \mathrm{~mm}$ in diameter was implanted above the VTA (4.8 $\mathrm{mm}$ posterior to bregma, $0.8 \mathrm{~mm}$ lateral to the midline, and 7.7 $\mathrm{mm}$ below dura) ipsilateral to the electrode. The 28-gauge injector cannula $(0.34 \mathrm{~mm}$ in diameter) extended $0.8 \mathrm{~mm}$ further into the VTA.

All rats were allowed $6 \mathrm{~d}$ to recover from surgery before training began. They were placed in a Plexiglas operant chamber $(30 \times 30 \times 28 \mathrm{~cm})$ with a 5-cm-wide lever protruding $4 \mathrm{~cm}$ into the chamber. Each rat was trained to bar press for $0.5 \mathrm{sec}$ trains of monophasic, 0.14 -msec-duration constantcurrent cathodal pulses. All rats pressed at rates $>40$ bar presses/min and received at least five sessions of training or baseline testing before formal testing began. During those preliminary sessions, currents were adjusted so that rate-frequency curves rose rapidly near $60 \mathrm{~Hz}$. These currents, which ranged from 130 to $850 \mu \mathrm{A}$ (mean, $440 \mu \mathrm{A}$ ) in different sites, were then held constant for each rat for all subsequent testing, during which only the frequency of testing was varied.

The stimulation parameters (large surface-area electrodes, shortduration pulses, and moderate currents) were chosen to maximize the direct activation of myelinated axons of the medial forebrain bundle and to minimize the direct activation of unmyelinated axons, such as dopamine axons (Segal and Bloom, 1974; Yeomans, 1975, 1979; Yeomans et al., 1985b, 1988; Bielajew and Shizgal, 1986; Koyama et al., 1987; Murray and Shizgal, 1996).

The rate of bar pressing was measured in an automated procedure (Campbell et al., 1985) at a range of frequencies, separated by $0.1 \mathrm{log}$ units (i.e., $25,32,40,50,63,79,100,130$, and $160 \mathrm{~Hz}$ ) or by $0.05 \log$ units in a few cases. When rats were able to generate stable rate-frequency curves every 10 min (i.e., which did not vary by $>0.1 \log$ units) without intervention by the experimenter, formal testing began. On at least $3 \mathrm{~d}$ before infusions began, a minimum of five rate-frequency curves were obtained each day to establish a baseline. These curves always included at least one frequency that generated maximal bar-pressing rates for this rat (always $>40$ bar presses/min) and at least one frequency that generated $<10$ bar presses/min. Each day during and after the oligo infusion, a minimum of five rate-frequency curves was obtained. The effects of the infusion on reward were assessed by the lateral shift in the rate-frequency curve (determined at the half-maximum rate), and the effects of the infusion on motor performance were assessed by the peak bar-pressing rates (Edmonds and Gallistel, 1977).

Oligo infusions. After the final day of baseline testing in each rat, an osmotic minipump was surgically implanted subcutaneously between the scapulae. A tube passed from the pump subcutaneously along the dorsal surface of the neck and exited the skin near the skull cap to connect with the cannula. The exposed tube was protected by U-shaped wires $(0.8 \mathrm{~mm}$ in diameter) attached to the skull cap, so that the rat could not manipulate and damage the tube. After $6 \mathrm{~d}$ of continuous infusion, the exposed tube was cut near the entry to the cannula and examined for moisture to assess whether fluid was still coming from the pump.

After $6 \mathrm{~d}$ recovery, most rats received a second miniosmotic pump, filled with another oligo, following the surgical procedure described above. Rate-frequency curves were tested during each of the $6 \mathrm{~d}$ of infusion and for 3-6 d of recovery. Each rat received one M5 antisense oligo and one control oligo in a counterbalanced order.

Histology. All rats tested behaviorally were killed under pentobarbital anesthesia at the end of the experiment. Intracardial perfusion of saline and $10 \%$ formalin was followed by removal of the brain from the skull. Each brain was soaked overnight in formalin saturated with sucrose and 
then coronally sectioned at $40 \mu \mathrm{m}$ in a cryostat. The Nissl-stained sections were examined for locations of electrode and cannula tips and for cellular damage near the cannula. The section nearest the cannula tip was projected onto the nearest atlas section (Paxinos and Watson, 1986). The lesion was displayed by tracing the area of greatest gliosis or tissue loss onto the atlas section.

Muscarinic receptors. To measure specific inhibition of M5 receptors, another set of nine rats was implanted with the VTA cannulae as described above, and after recovery, M5 oligos were infused via an osmotic minipump as described above. Five rats were infused with the M5 antisense oligo, and four were inf used with the M5 missense oligo. After $6 \mathrm{~d}$ of inf usion, all rats were killed by decapitation, their brains were removed, and the ventral tegmentum was dissected by hand. Two coronal cuts of the brains were made: at the rostral end of the mammillary bodies and the rostral end of the pons. Then, the medial lemniscus was observed at the rostral end of the block, and a horizontal cut was made to create a tissue block of the ventral tegmentum, which was then sectioned at the midline. These blocks were placed on dry ice and coded.

The density of M5 receptors was measured in grouped samples using blind procedures by D.D.F., with the assay methods described previously (Flynn et al., 1997; Reever et al., 1997). Muscarinic receptors other than M5 were blocked by pretreating tissue in $30 \mu \mathrm{g} / \mathrm{ml}$ green mamba toxin and $1 \mu \mathrm{M}$ AQ-RA 741 . This procedure blocks $>99 \%$ of M1, M2, and M4 receptors and $>85 \%$ of M3 receptors, while sparing the majority of M5 receptors. The remaining receptors are measured by binding with $\left[{ }^{3} \mathrm{H}\right] N$-methyl-scopolamine.

\section{RESULTS}

\section{Histology}

Electrodes were located in the medial forebrain bundle at levels from the anterior commissure (rat K18) to the lateral hypothalamus (Fig. 1, top). Injector cannula tips were located within a 2-mm-diameter region in and around the VTA, with most tips ending near the VTA (Fig. 1, bottom). The most effective sites, in general, were those nearest the lateral VTA or medial SN (e.g., J3 and K11) at $\sim 5.0 \mathrm{~mm}$ behind bregma or just dorsal to this part of the VTA and SN (M25 and M24). The least effective site (where a rate-frequency curve shift of only $13 \%$ was observed) was for rat K18, whose injector tip site was located in the posterior hypothalamus.

\section{Brain-stimulation reward: effect of infusions}

Typical rate-frequency curves for baseline conditions are shown in Figure 2, top. In all cases, at the lowest frequencies only a few bar presses per minute occurred, and at some intermediate frequency bar-pressing rates increased rapidly, whereas at higher frequencies bar-pressing rates approached an asymptote at a bar-pressing rate $>40$ bar presses/min. Peak bar-pressing rates in baseline conditions were very stable for each rat in all conditions. For each of the three oligo groups, mean peak bar-pressing rates ranged from 60 to 64 bar presses/min, and frequencies at half-maximum rates ranged from a mean of 57 to $62 \mathrm{~Hz}$. These results indicate that the groups were well matched for the efficacy of their stimulating electrode sites.

During the infusion of M5 antisense oligo, the rate-frequency curves shifted to the right, usually beginning 20-24 hr after infusion began (day 1) and shifting gradually over the next few days. The frequency required to maintain half-maximal bar-pressing rates on each day was measured by interpolation. For rat M25 the curves shifted to the right for the first $5 \mathrm{~d}$, reaching a peak increase in required frequency of $75 \%$ (Fig. 2, middle). The tube from the pump to the cannula was cut after testing on day 6 , and the rate-frequency curves shifted back to the baseline levels in the next 2-3 d. Individual $t$ tests (corrected for multiple comparisons with the Bonferroni method) showed that the frequencies required to reach half-maximal rates shifted significantly from baseline levels on day 1 and days 3-8 but were not significantly different on day 2 and days $10-12$ for this rat.

In Figure 3, top, smaller shifts on the first infusion of M5 antisense (i.e., for rats M24 and M28) are shown. Control inf usions (Fig. 3, bottom) had only slight effects on rate-frequency curves. For example, in Figure 2, bottom, an infusion of M5 sense in M25 showed a maximum shift of $12 \%$ on day 6 . These results were significantly different from baseline levels only on days 6,8 , and 10
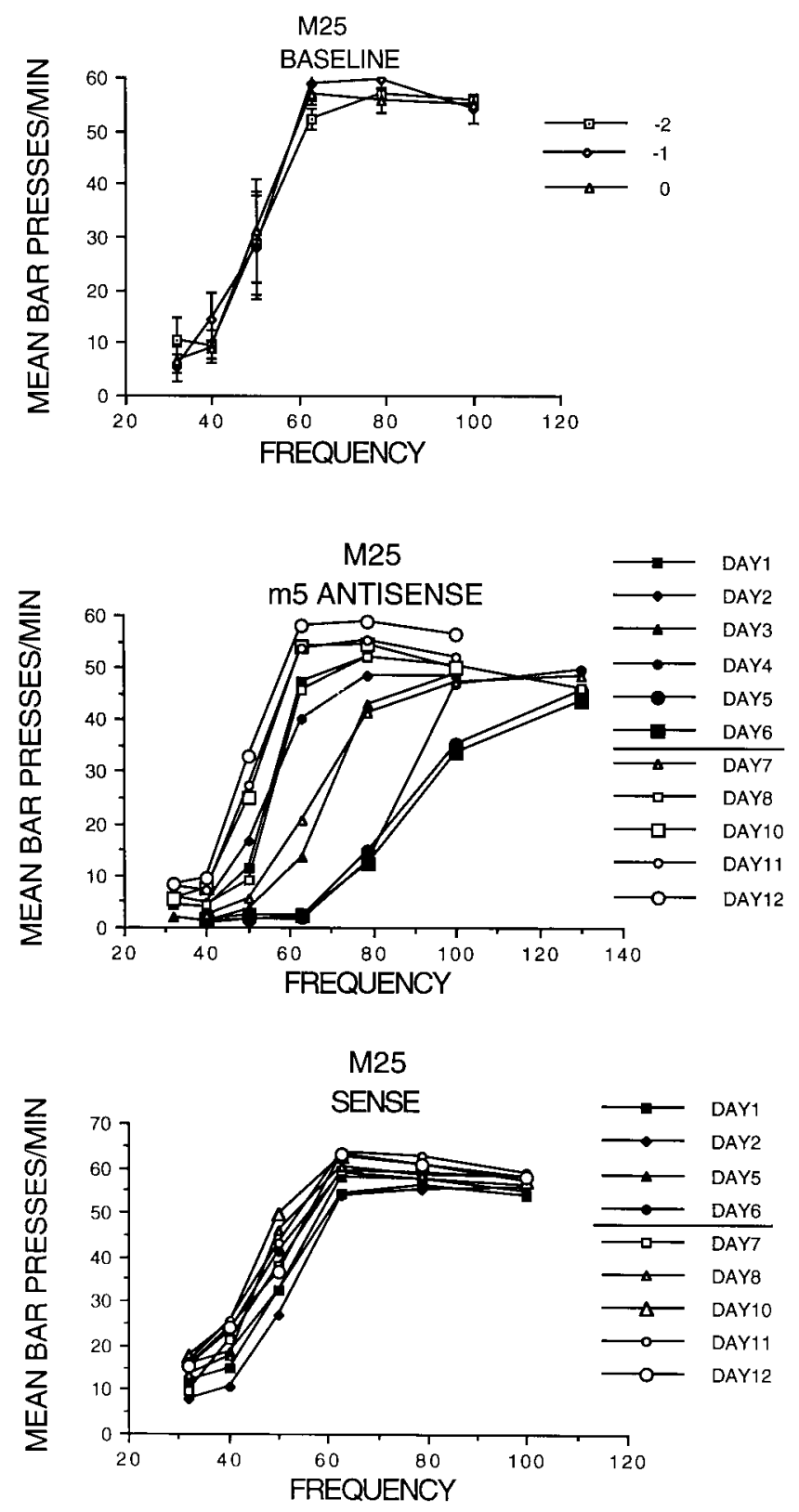

Figure 2. Effects of oligo infusions in the VTA on brain-stimulation reward rate-frequency curves for rat M25. Top, Baseline curves for $3 \mathrm{~d}$ before infusions (days -2 to 0 ) are shown. Middle, Rate-frequency curve shifts induced by M5 antisense oligo inf usions on days 1-6 and recovery on days 7-12 are shown. Bottom, Inf usion of M5 sense oligo had little effect on rate-frequency curves (days 1-12).

and then by shifting significantly below the baseline. In Figure 3, M5 missense produced a maximum shift of $7 \%$ on day 6 for rat M28.

Figure 4 shows the mean shift in required frequency for antisense, sense, and missense oligo groups, excluding K18. The logarithmic plot shows geometric means, with the group error bars shown in log units. In general, the frequency shift increased over infusion days (indicating inhibition of brain-stimulation reward by the oligos) and then decreased after the infusion was terminated (indicating recovery from inhibition). These groups were compared using ANOVA on the final 3 baseline days (days -2 to 0 , the final 3 infusion days (days 4-6), and the final $3 \mathrm{~d}$ of recovery (days 10-12). The groups were significantly different on the final 3 inf usion days $\left[F_{(2,84)}=28.8 ; p<0.001\right]$ but not on the baseline days $(p>0.5)$ or on the final 3 recovery days $\left[F_{(2,69)}=2.5 ; p=0.09\right]$. On individual days, the antisense group scores were significantly higher than were those of the sense group on days 1 and 5-7 and 

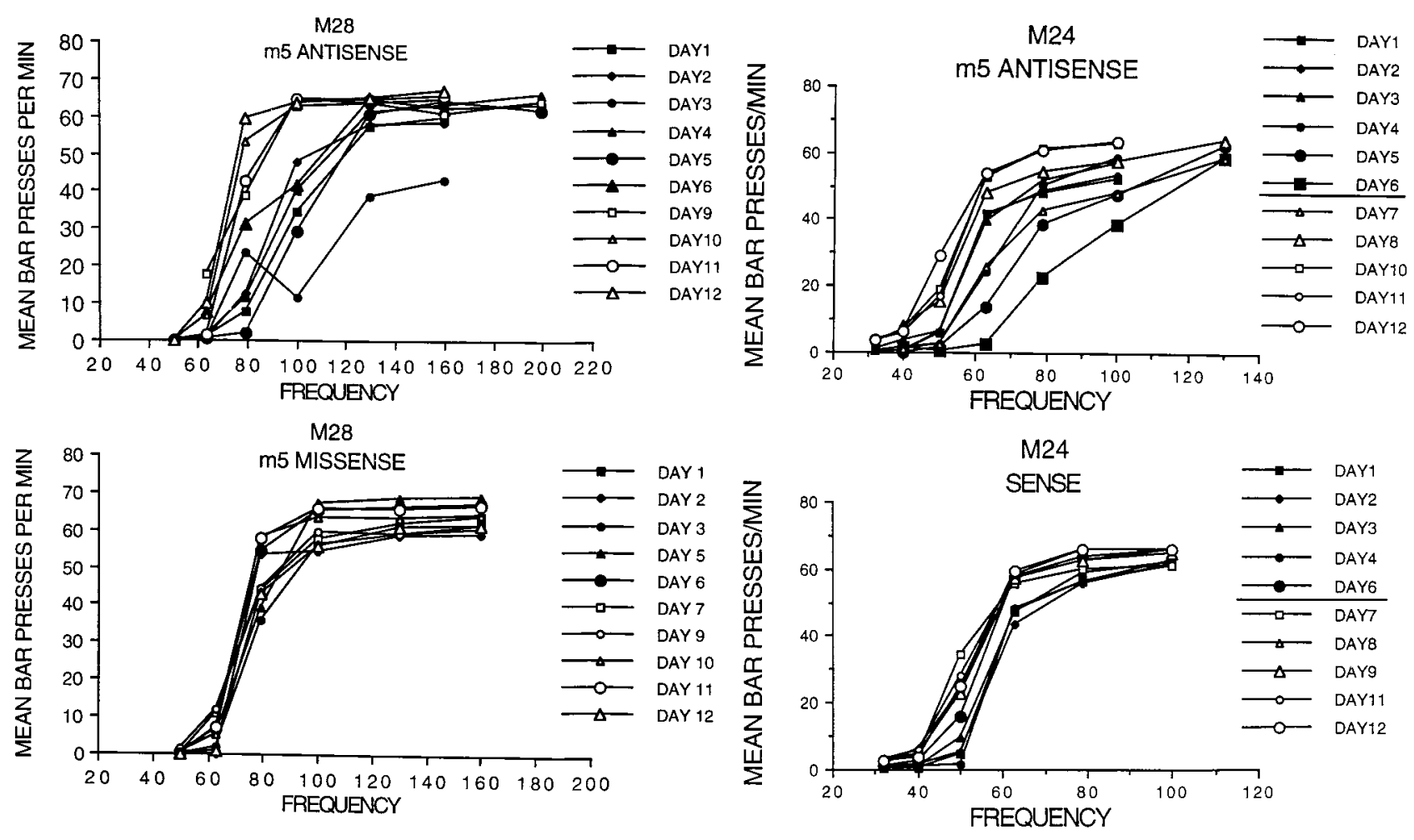

Figure 3. Examples of rate-frequency curve shifts induced by oligos. Top, Antisense for the M5 receptor increased frequencies from day 1 to 6 , followed by recovery on days 7-12. Bottom, Rate-frequency curves shifted little during and after infusions of M5 missense (left) or sense (right) oligos.

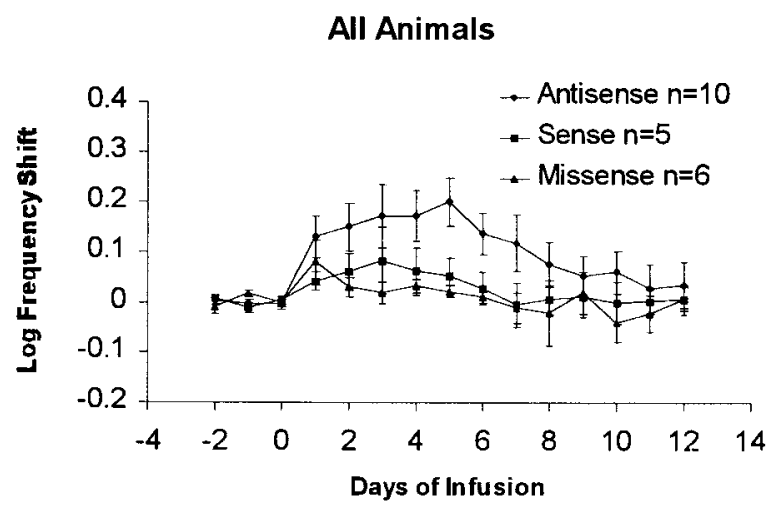

Figure 4. Mean effects of oligos on rate-frequency curve shifts in all rats. Each curve represents the mean log frequency shift for the antisense, mismatched, or sense groups, with SEMs shown. Infusions began late on day 0 and ended on day 6 .

higher than were those of the missense group on days 2-7, but the control groups were never reliably different. The differences on day 7 indicate that the recovery was not complete $24 \mathrm{hr}$ after the infusion was terminated.

Although control oligos produced slight increases on days 1-3, followed by decreases to near baseline levels by day 6 , the antisense oligo increased the required frequency steadily from day 1 to 5 . There was no main effect of days, however $(F=0.13 ; p=0.98)$, and the one-way interaction of oligos versus days was not significant (general linear model, $F=2.79$; df $=2,1 ; p=0.10, \mathrm{NS}$ ).

Rats given M5 antisense for the first infusion (Fig. 5, top) had larger shifts (peaking at $78 \%$ on day 5) than did rats given M5 antisense for the second infusion (Fig. 5, bottom; peaking at $31 \%$ on day 3 or at $38 \%$ if K18 is excluded). In particular, the first M5 antisense oligo infusion had a significantly greater effect on days $4-6$ than did the second antisense infusion $\left[F_{(1,7)}=6.85 ; p<0.05\right]$. This suggests that the sensitivity of the reward system to M5 antisense was less when given as a second infusion after a control inf usion. The antisense infusions shifted the curves more than the control infusions did, whether the oligos were given on the first or the second infusion.

\section{Recovery from infusions}

The recovery from the M5 antisense infusions occurred gradually between day 7 and 10 in the 10 sites tested. Over all recovery days (7-12) the effect of antisense oligo was significantly different from baseline (antisense recovery vs baseline, $t=6.89 ; p<0.001$ ), whereas the effects of control oligos were not significantly different from baseline. The results for the antisense condition were still above those for the two control conditions (main effect of oligos, $F=12.34 ; p<0.0007)$.

In six of the nine sites (J2, K5, K18, M24, M25, and M28) showing an effect of antisense, the required frequencies recovered to within $5 \%$ of baseline levels by days $9-12$, but in two sites (J3 and $\mathrm{K} 11$ ), the frequencies did not return completely to baseline levels. In control conditions, results showed recovery to within 5\% of baseline, except for J4 (which was given M5 sense) and K5 (which was given M5 missense). All five sites showing complete recovery in both conditions showed minimal postmortem damage near the cannula tip, that is, a glial scar that was $<1 \mathrm{~mm}$ in diameter. The four sites showing incomplete recovery ( J3, J4, K5, and K11) all showed damage around the cannula tip of 1.3-2.5 mm diameter that included some partial damage to the VTA or medial $\mathrm{SN}$ in each case. The means of all sites showing some damage are shown in Figure 6, bottom. Therefore, more damage near the cannula tip was associated with incomplete postinfusion recovery from one of the two infusions.

The effects of M5 antisense oligo were not caused primarily by damage, however. Five of the sites showed no damage to the VTA and/or SN and showed complete recovery to within 5\% of baseline. Still these sites showed a rate-frequency curve shift that was $>35 \%$ during the M5 antisense infusion but was always $<15 \%$ during the control inf usion (Fig. 6, top). Therefore, even when damaged sites were excluded, the antisense oligo shifted thresholds by five times that of control oligos $(t=3.36 ; p<0.05)$. Only the antisense oligo 


\section{First Infusion}

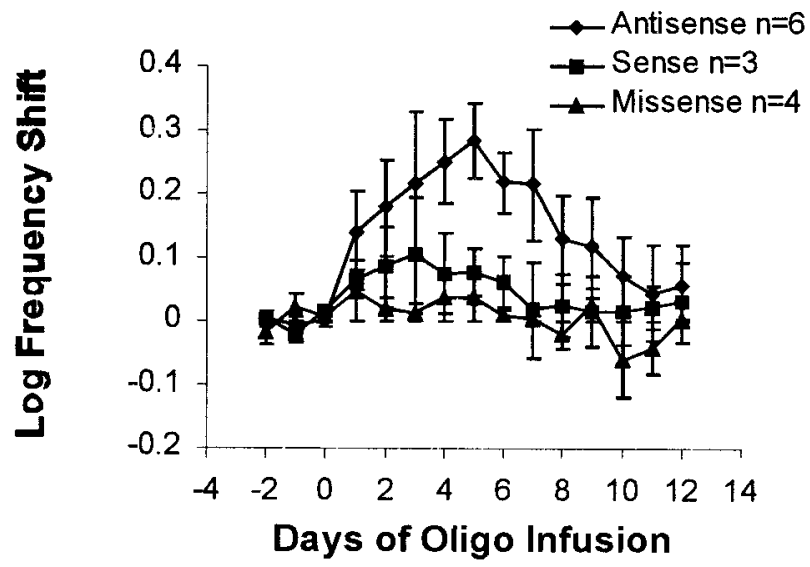

Second Infusion

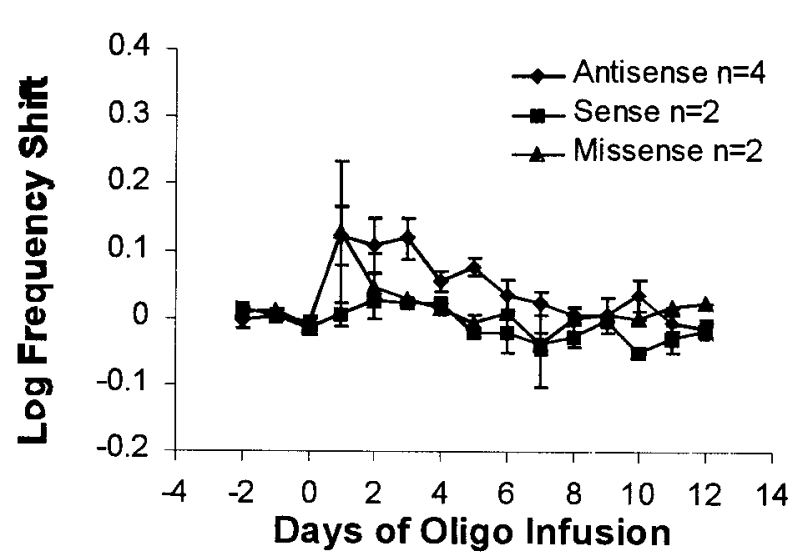

Figure 5. Effects of the antisense oligo on rate-frequency curve shifts for first and second infusions. The results are divided into those sites that received the M5 antisense oligo on the first infusion (days $1-6$; top) or on the second infusion (days 13-18 but labeled days $1-6$ here; bottom). The antisense infusion was more effective and longer lasting on the first infusion.

shifted thresholds significantly during the $6 \mathrm{~d}$ of infusion versus baseline conditions (antisense vs baseline, $t=4.82, p<0.01$; sense vs baseline, $t=2.21$, NS; missense vs baseline, $t=2.22$, NS). The shifts were smaller for all groups in the undamaged category than for the unselected group means of Figure 4, as were the error bars. Recovery after infusion was complete and occurred faster in undamaged than in damaged sites. Even in the two sites that showed substantial tissue damage and incomplete recovery, the shifts during the M5 antisense infusion were 1.9 and 5.3 times larger than that of the residual effect after infusion.

\section{Peak bar-pressing rates}

Peak bar-pressing rates were lower in most animals (in all groups) on the day after surgical implantation of the osmotic minipump but often recovered by day 2 or 3 . In several sites (K11, M25, and J3) on days when the antisense oligo was maximally effective, peak bar-pressing rates were found to be reduced compared with baseline levels. These rates recovered completely to baseline levels by days 9-12. Peak bar-pressing rates were less affected by control inf usions.

\section{Inhibition of M5 receptors}

M5 receptors were assayed by the use of a subtraction method (Flynn et al., 1997; Reever et al., 1997) in coded ventral tegmental tissue samples taken from rats receiving $6 \mathrm{~d}$ of antisense or missense oligo inf usions into the VTA and/or SN region as described

\section{Undamaged Sites}

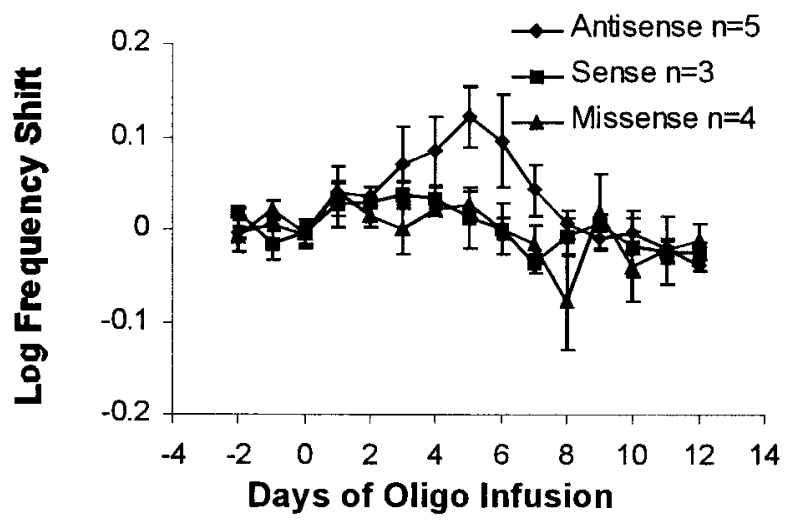

\section{Damaged Sites}

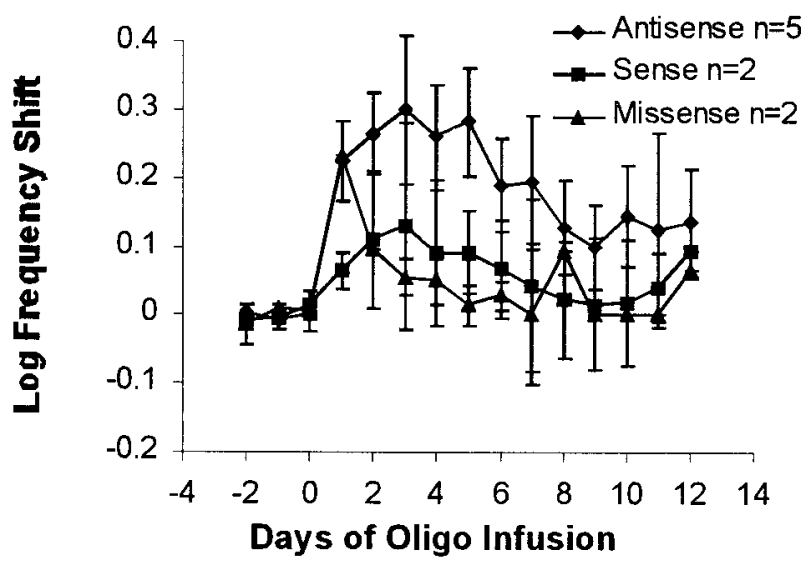

Figure 6. Top, Effects of the oligo infusions on days $0-6$ on rate-frequency curve shifts for the four VTA cannula sites showing minimal histological damage and complete recovery. Bottom, Effects of the oligos in rats in which VTA or SN cell damage was observed.

in the behavioral studies. In ventral tegmental brain samples taken contralateral to the cannulae, no difference in the estimated density of M5 receptors was found between missense- and antisensetreated rats (Fig. 7). By contrast, in samples taken from the side where antisense oligos were infused, M5 receptors were significantly reduced by $25 \%$ compared with the contralateral side and by $23 \%$ relative to the missense controls. This indicates that M5 receptors were significantly reduced by the M5 antisense oligo inf usions on the side of the cannula but that infusions did not cross the midline sufficiently to inhibit M5 receptors contralaterally.

\section{DISCUSSION}

Oligos infused for $6 \mathrm{~d}$ near the VTA produced sequence-specific shifts in the frequency required to produce brain-stimulation reward in medial forebrain bundle sites. Antisense oligo for the M5 receptor gene increased thresholds by a mean of $78 \%$ if given on the first infusion and by $31 \%$ if given on the second infusion into the VTA. Control oligos produced only slight effects (mean shifts $<15 \%$ in all conditions).

Antisense for the M5 receptor gene also reduced M5 receptor density in the ventral tegmentum ipsilateral to the cannula by $25 \%$ relative to missense controls. Because there was no change in the estimated M5 receptor density on the contralateral side, the oligos acted mainly on one side of the brain. Therefore, it is likely that M5 antisense oligos were acting maximally to reduce M5 receptors within $\sim 1 \mathrm{~mm}$ of the injection site and not throughout the larger ventral tegmental samples. This estimate is consistent with the 


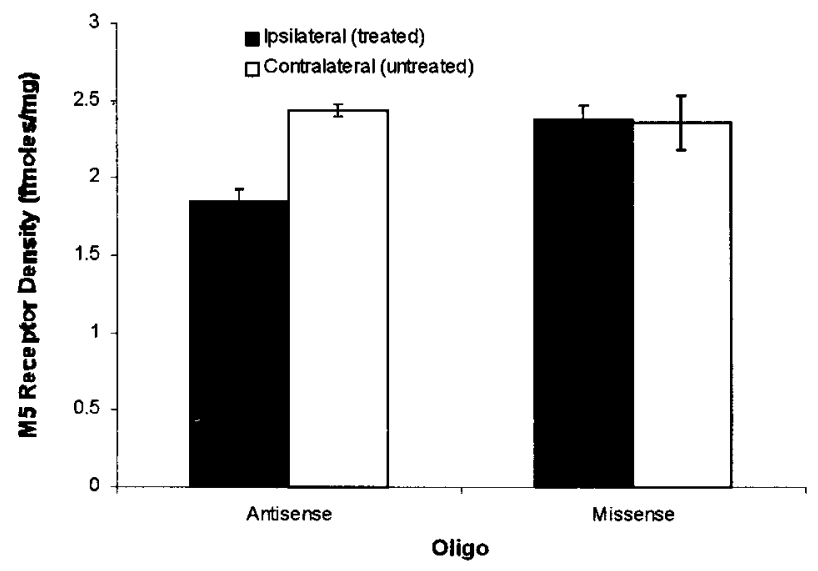

Figure 7. Density of M5 muscarinic receptors in the ventral tegmentum after unilateral infusions into the VTA estimated with the subtraction method of Flynn et al. (1997). M5 receptor density was decreased ipsilateral to the antisense infusion but not by the missense infusion. The volume of tissue sampled in the ventral tegmentum included all of the VTA and SN, so the local infusions in the VTA reduced M5 density in only a part of that tissue, as indicated by the lack of effect on the contralateral tissue.

behavioral results, indicating stronger effects when cannula tips were in or just dorsal to the VTA and/or SN and weaker effects when the tips were $\sim 1 \mathrm{~mm}$ away.

Chronic infusion of oligos into the VTA has the advantage of continuous delivery of the agent near neurons that express the protein of interest (Neckers et al., 1995). In this case, dopamine cells of the VTA express M5 receptors and are important for brain-stimulation reward. This local infusion method is useful because of the poor diffusion of oligos from the blood stream and cerebral ventricles and the short half-life of phosphodiester oligos in brain tissue (Neckers et al., 1995).

The risk is that continuous local infusion of oligos may damage the cells, so that the behavioral change may reflect tissue damage rather than receptor inhibition. Indeed, in two sites where damage to the VTA and medial SN was observed postmortem, required frequencies increased by the largest amounts, and required frequencies failed to return completely to baseline levels after termination of antisense infusions. In four sites without damage to the VTA or SN, however, large shifts in the required frequency during M5 antisense infusion (but not control infusions) were followed by complete recovery after infusion. Even when damaged sites were excluded, increases in the required frequency after M5 antisense oligo inf usions were several times larger than that of control oligos. Therefore, the increases in the required frequency are caused by the effects of the M5 antisense oligo and not by tissue damage measured postmortem.

It could be argued that temporary damage, not observed by postmortem histology and caused by the antisense oligo but not the control oligos, led to the present effects. This argument does not explain how this assumed temporary neuronal damage could be mediated by the M5 antisense, but not the almost-identical M5 missense oligo, unless the damage is somehow related to the loss of the M5 receptors. We, therefore, conclude that M5 receptor changes are the likely cause of the rate-frequency curve shifts.

Peak bar-pressing rates are considered a measure of peak performance capacity (Edmonds and Gallistel, 1977) and, as such, assess whether the oligo treatments were behaviorally toxic to the rats. In previous studies, single injections into the VTA of the muscarinic antagonist atropine $(30 \mu \mathrm{g})$ or the nicotinic antagonist dihydro- $\beta$-erythroidine (30 or $60 \mu \mathrm{g}$ ) decreased peak bar-pressing rates by up to $20 \%$ in sites where frequency threshold shifts were maximal (Yeomans and Baptista, 1997). Here, peak bar-pressing rates decreased in several cases, by varying amounts. Small decreases in the peak bar-pressing rate, such as that found in Figure 2, middle, for M25 in the present results, are consistent with either (1) expected effects of muscarinic receptor inhibition or (2) tem- porary sequence-specific behavioral toxicity. The two largest decreases in peak bar-pressing rates $(>30 \%$ compared with baseline rates on several days) were found in the M5 antisense conditions for $\mathrm{J} 3$ and $\mathrm{K} 11$, conditions showing incomplete recovery after infusion and damage near the cannulae postmortem, suggesting more severe anatomical and behavioral toxicity in these two cases.

\section{Changes in M5 receptors}

Evidence of selective M5 receptor inhibition was obtained from a matched set of rat brains inf used in vivo with antisense or missense oligos for $6 \mathrm{~d}$. After death, the ventral tegmental samples were treated with inhibitors of M1-M4 muscarinic receptors. The antisense treatments strongly inhibited the remaining muscarinic receptors in the ventral tegmentum on the side of the infusion but did not affect the contralateral ventral tegmentum, indicating that the infusions affected a local region near the infusion site. The $25 \%$ reduction in the large ventral tegmental samples is consistent with stronger inhibition of M5 receptors in a small region near the VTA infusion site critical for brain-stimulation reward and consistent with the size of the behavioral effects observed. Oligos targeting the M1 muscarinic receptor have been found previously to produce selective inhibition of that receptor but not the M2 receptor (Zang et al., 1994). We did not measure changes in other receptor subtypes, however, so the present results do not exclude possible sequence-specific effects of the M5 antisense oligo on other receptors.

Several studies have found that oligos targeted at various brain proteins can alter behavioral responses (Wahlestedt et al., 1993; Zhang and Creese, 1993; Adams et al., 1994; Akabayashi et al., 1994; Ogawa et al., 1994; Tischmeyer et al., 1994; Neckers et al., 1995). In those studies, control oligos often induced smaller, but reliable, behavioral changes relative to baseline, similar to those observed here. It is not known whether these smaller shifts are caused by nonspecific effects of the oligos or by specific hybridization with other genes and/or mRNAs.

\section{Conclusions}

The present results support the idea that M5 muscarinic receptors in the VTA are important for the cholinergic activation of dopamine cells believed crucial to brain-stimulation reward in medial forebrain bundle sites (Yeomans et al., 1985a,b, 1993). These results are consistent with previous results using nonselective muscarinic blockers but show further that inhibition of the M5 receptor subtype is responsible for most of that effect. According to this interpretation, M5 muscarinic receptors occupy a nodal point in the converging reward systems that activate mesolimbic dopamine systems (Yeomans, 1995).

\section{REFERENCES}

Adams JU, Chen X, DeRiel JK, Adler MW, Liu-Chen L-Y (1994) Intracerebroventricular treatment with an antisense oligodeoxynucleotide to $\mathrm{K}$-opioid receptors inhibited $\mathrm{K}$-agonist-induced analgesia in rats. Brain Res 667:129-132.

Akabayashi A, Wahlestedt C, Alexander JT, Leibowitz SF (1994) Specific inhibition of endogenous neuropeptide $\mathrm{Y}$ synthesis in arcuate nucleus by antisense oligonucleotides suppresses feeding behavior and insulin secretion. Mol Brain Res 21:55-61.

Bielajew C, Shizgal P (1986) Evidence implicating descending fibers in self-stimulation of the medial forebrain bundle. J Neurosci 6:919-929.

Blaha CD, Winn P (1993). Modulation of dopamine efflux in the striatum following cholinergic stimulation of the substantia nigra in intact and pedunculopontine tegmental nucleus-lesioned rats. J Neurosci 13:1035-1044

Blaha CD, Allen LF, Inglis WI, Das S, Latimer MP, Vincent SR, Winn P (1996) Modulation of dopamine efflux in the nucleus accumbens after cholinergic stimulation of the ventral tegmental area in intact, pedunculopontine tegmental nucleus-lesioned, and laterodorsal tegmental nucleus-lesioned rats. J Neurosci 16:714-722.

Bolam JP, Francis CM, Henderson Z (1991) Cholinergic input to dopaminergic neurons in the substantia nigra: a double immunocytochemical study. Neuroscience 41:483-494.

Bonner TI, Buckley NJ, Young AC, Brann MR (1987) Identification of a family of muscarinic acetylcholine receptor genes. Science 237:527-532.

Bonner TI, Young A, Brann MR, Buckley NJ (1988) Cloning and expression of the human and rat $\mathrm{m} 5$ muscarinic receptor genes. Neuron $1: 403-410$. 
Campbell KA, Evans G, Gallistel CR (1985) A microcomputer-based method for physiologically interpretable measurement of the rewarding efficacy of brain stimulation. Physiol Behav 35:395-403.

Clarke PBS, Pert A (1985) Autoradiographic evidence for nicotine receptors on nigrostriatal and mesolimbic neurons. Brain Res 348:355-358.

Corrigall WA, Coen KM (1989) Nicotine maintains robust selfadministration in rats on a limited-access schedule. Psychopharmacology (Berl) 104:473-478.

Corrigall WA, Franklin KBJ, Coen KM, Clarke PBS (1992) The mesolimbic dopaminergic system is implicated in the reinforcing effects of nicotine. Psychopharmacology (Berl) 107:285-289.

Corrigall WA, Coen KM, Adamson KL (1994) Self-administered nicotine activates the mesolimbic dopamine system through the ventral tegmental area. Brain Res 653:278-284.

Crooke ST (1992) Therepeutic applications of oligonucleotides. Annu Rev Pharmacol Toxicol 32:329-376.

Edmonds DE, Gallistel CR (1977) Reward versus performance in selfstimulation: electrode specific effects of alpha-methyl-p-tyrosine on reward in the rat. J Comp Physiol Psychol 91:962-974.

Flynn DD, Reever CM, Ferrari-DiLeo G (1997) Pharmacological strategies to selectively label and localize muscarinic receptor subtypes. Drug Dev Res 40:104-116.

Fujimoto K, Ikeguchi K, Yoshida M (1990) Decrease and recovery of choline acetyltransferase activity in medial thalamus and ventral tegmental area after destruction of pedunculopontine areas in the rat. Neurosci Res 9:48-53.

Futami T, Takakusaki E, Kitai ST (1995) Glutamatergic and cholinergic inputs from the pedunculopontine tegmental nucleus to dopamine neurons in the substantia nigra pars compacta. Neurosci Res 21:331-342.

Gallistel CR, Karras D (1984) Pimozide and amphetamine have opposite effects on the reward summation function. Pharmacol Biochem Behav 20:73-77.

Imperato A, Mulas A, DiChiara G (1986) Nicotine preferentially stimulates dopamine release in the limbic system of freely moving rats. Eur J Pharmacol 132:337-338.

Kofman O, Yeomans JS (1989) Cholinergic antagonists in ventral tegmentum elevate frequency thresholds for lateral hypothalamic and brainstem self-stimulation. Pharmacol Biochem Behav 31:547-559.

Kofman O, McGlynn S, Olmstead MC, Yeomans JS (1990) Differential effects of atropine, procaine and dopamine in the rat ventral tegmentum on lateral hypothalamic rewarding brain stimulation. Behav Brain Res 38:55-68.

Koyama Y, Jodo E, Kayama Y (1987) Electrophysiology of ascending, possibly cholinergic neurons in the rat laterodorsal tegmental nucleus: comparison with monoamine neurons. Neurosci Lett 77:277-282.

Kubo T, Fukuda K, Mikami A, Maeda A, Takahashi H, Mishina M, Haga K, Ichiyama A, Kangawa K, Kojima M, Matsuo H, Hirose T, Numa S (1986) Cloning, sequencing and expression of complementary DNA encoding the muscarinic acetylcholine receptor. Nature 323:411-416.

Lacey MG, Calabresi P, North RA (1990) Muscarine depolarizes substantia nigra zona compacta and ventral tegmental neurons in vitro through M1-like receptors. J Pharmacol Exp Ther 253:395-400.

Levey AI, Kitt CA, Simonds WF, Price DL, Brann MR (1991) Identification and localization of muscarinic acetylcholine receptor proteins in brain with subtype-specific antibodies. J Neurosci 11:3218-3226.

McCarthy MM, Schlenker EH, Pfaff DW (1993) Enduring consequences of neonatal treatment with antisense oligodeoxynucleotides to estrogen receptor messenger ribonucleic acid on sexual differentiation of rat brain. Endocrinology 133:433-439.

Murray B, Shizgal P (1996) Behavioral measures of conduction velocity and refractory period for reward-relevant axons in the anterior $\mathrm{LH}$ and VTA. Physiol Behav 59:643-652.

Museo E, Wise RA (1990) Locomotion induced by ventral tegmental microinjections of a nicotinic agonist. Pharmacol Biochem Behav 35:735-737.

Neckers LM, Geselowitz DA, Chavany C (1995) Pharmacokinetics and delivery of oligonucleotides to the brain. In: Delivery strategies for antisense oligonucleotide therapeutics (Akhtar S, ed), pp 61-69. Boca Raton, FL: CRC

Nissell M, Nomikos GG, Svensson TH (1994) Systemic nicotine-induced dopamine release in the rat nucleus accumbens is regulated by nicotinic receptors in the ventral tegmental area. Synapse 16:36-44.

Ogawa S, Olazabal UE, Parhar IS, Pfaff DW (1994) Effects of intrahypothalamic administration of antisense DNA for progesterone receptor mRNA on reproductive behavior and progesterone receptor immunoreactivity in female rats. $\mathbf{J}$ Neurosci 14:1766-1774.
Paxinos G, Watson C (1986) The rat brain in stereotaxic coordinates, 2nd Edition. New York: Academic.

Peralta EG, Winslow JW, Peterson GL, Smith DH, Ashkenazi A, Ramachandran J, Schimerlick MI, Capon DJ (1987) Primary structure and biochemical properties of an M2 muscarinic receptor. Science 236:600-605.

Phillips AG, Fibiger HC (1978) The role of dopamine in maintaining intracranial self-stimulation in the ventral tegmentum, nucleus accumbens and medial prefrontal cortex. Can J Psychol 32:58-66.

Phillips MI, Gyurko R (1995) In vivo applications of antisense oligonucleotides for peptide research. Regul Pept 59:131-141.

Rada PV, Mark GP, Yeomans JS, Hoebel BG (2000) Acetylcholine release in ventral tegmental area by hypothalamic self-stimulation, eating and drinking. Pharmacol Biochem Behav 55:131-141.

Reavill C, Stolerman IP (1990) Locomotor activity in rats after administration of nicotinic agonists intracerebrally. Br J Pharmacol 99:273-278.

Redgrave P, Horrell RI (1976) Potentiation of central reward by localized perfusion of acetylcholine and 5-hydroxytryptamine. Nature 262:305-307.

Reever CM, Ferrari-DiLeo G, Flynn DD (1997) The M5 (m5) receptor subtype: fact or fiction? Life Sci 60:1105-1115.

Segal M, Bloom FE (1974) The action of norepinephrine in the rat hippocampus. II: Activation of the input pathway. Brain Res 72:99-114.

Stellar JR, Corbett D (1989) Regional neuroleptic microinjections indicate a role for nucleus accumbens in lateral hypothalamic self-stimulation reward. Brain Res 477:126-143.

Tischmeyer W, Grimm R, Schicknick H, Brysch W, Schlingensiepen K-H (1994) Sequence-specific impairment of learning by c-jun antisense oligonucleotides. NeuroReport 5:1501-1504.

Vilaro MT, Palacios JM, Mengod G (1990) Localization of m5 muscarinic receptor mRNA in rat brain examined by in situ hybridization histochemistry. Neurosci Lett 43:31-36.

Wagner RW (1994) Gene inhibition using antisense oligodeoxynucleotides. Nature 372:333-335.

Wahlestedt C (1994) Antisense oligonucleotide strategies in neuropharmacology. Trends Pharmacol Sci 15:42-46.

Wahlestedt C, Pich EM, Koob GF, Yee F, Heilig M (1993) Modulation of anxiety and neuropeptide Y-Y1 receptors by antisense oligodeoxynucleotides. Science 259:528-531.

Weiner DM, Levey AI, Brann MR (1990) Expression of muscarinic acetylcholine and dopamine receptor mRNAs in rat basal ganglia. Proc Natl Acad Sci USA 87:7050-7054.

Wise RW (1978) Catecholamine theories of reward: a critical review. Brain Res 152:215-247.

Yasuda RP, Ciesla W, Flores LR, Wall SJ, Li M, Satkus SA, Weisstein JS, Spangnola BV, Wolfe BB (1993) Development of antisera for $\mathrm{m} 4$ and $\mathrm{m} 5$ muscarinic cholinergic receptors: distribution of $\mathrm{m} 4$ and $\mathrm{m} 5$ receptors in rat brain. Mol Pharmacol 43:149-157.

Yeomans JS (1975) Ouantitative measurement of neural post-stimulation excitability with behavioral methods. Physiol Behav 15:593-602.

Yeomans JS (1979) Absolute refractory periods of self-stimulation neurons. Physiol Behav 22:911-919.

Yeomans JS (1995) Role of tegmental cholinergic neurons in dopaminergic activation, antimuscarinic psychosis and schizophrenia. Neuropsychopharmacology 12:3-16.

Yeomans JS, Baptista M (1997) Both nicotinic and muscarinic receptors in ventral tegmental area contribute to brain-stimulation reward. Pharmacol Biochem Behav 57:915-921.

Yeomans JS, Kofman O, McFarlane V (1985a) Cholinergic involvement in lateral hypothalamic self-stimulation. Brain Res 329:19-26.

Yeomans JS, Mercouris N, Ellard C (1985b) Refractory period estimates are lengthened by reducing electrode tip exposure or increasing current. Behav Neurosci 99:913-928.

Yeomans JS, Maidment NT, Bunney BS (1988) Excitability properties of medial forebrain bundle axons of putative A10 dopamine cells. Brain Res 450:86-93.

Yeomans JS, Mathur A, Tampakeras M (1993) Rewarding brain stimulation: role of tegmental cholinergic neurons that activate dopamine neurons. Behav Neurosci 107:1077-1087.

Yeomans JS, Baptista M, Takeuchi J, Kofman O, Ralph MR (1995) The role of nicotinic and muscarinic (m5) receptors in the ventral tegmental area in intracranial self-stimulation. Soc Neurosci Abstr 21:732.

Zang Z, Florijn W, Creese I (1994) Reduction in muscarinic receptors by antisense oligonucleotide. Biochem Pharmacol 48:225-228.

Zhang M, Creese I (1993) Antisense oligodeoxynucleotide reduces brain D2 receptors: behavioral correlates. Neurosci Lett 161:223-226. 